\title{
A EDUCAÇÃO COMO UM DIREITO FUNDAMENTAL DE NATUREZA SOCIAL
}

\section{EDUCATION AS A FUNDAMENTAL LAW OF SOCIAL NATURE}

\section{PAULO SERGIO BANDEIRA}

Mestrando em Direito Empresarial e Cidadania pelo Centro Universitário Curitiba UNICURITIBA. Email: paulobandeira@rechadvogados.com.br

\section{INTRODUÇÃO}

A educação é peça chave para que se alcance o desenvolvimento do país, sendo uma ferramenta imprescindível na busca de uma nação próspera e solidária, cuja oferta é garantida constitucionalmente pela Constituição Federal na qual se descreve direitos que propiciam ao cidadão o amplo acesso a esse serviço público.

Tendo como escopo discorrer sobre como a educação é vista como um direito social, a pesquisa se destina a demonstrar os deveres do Estado e da família nessa função constitucional, na medida em que se investigará o surgimento dessa norma social e como ela se encaixa em nossa lei maior. Igualmente se buscará descrever os contornos do direito social da educação de modo a deixar claro o entendimento de que se trata de um direito público subjetivo, cabendo ainda demonstrar em que medida a gratuidade da educação pública do ensino básico e seu acesso devem ser obrigatoriamente ofertados pelo Estado, não se olvidando do princípio da igualdade, almejando como ponto de chegada o acesso educação para todos sem qualquer distinção discriminatória.

Por evidente que esta pesquisa não tem como propósito esvaziar todas as hipóteses de debate sobre o tema e não se destinará a levantar discussões sobre os 


\section{Personalidade Acadêmica Homenageada:}

Carlos Aurélio Mota de Souza (Universidade Ibirapuera - UNIB)

conteúdos e qualidade do ensino básico, bem como não se direcionará a aventar a competência dos entes federativos para a prestação do serviço educacional.

É importe frisar que o escopo desta pesquisa se destina, sobretudo, a trazer noções gerais sobre a educação pública no ensino básico como um direito social e os efeitos dessa prerrogativa para o cidadão, não sendo objeto do trabalho constatar se esse direito vem sendo oferecidos na prática, ao passo que não caberá neste trabalho avaliar ou constatar dados relativos a oferta de vagas, investimentos ou quaisquer dados econômicos relativos à educação.

\section{METODOLOGIA}

A presente pesquisa, realizando uma revisão bibliográfica e dedutiva, debruçar-se-á sobre a análise de alguns pontos relevantes do direito à educação, explorando a doutrina atual e legislações pertinentes ligadas ao direito educacional.

\section{REVISÃO DE LITERATURA}

A educação nem sempre esteve entre os mais importantes reclames da sociedade ao longo da história, posto que as classes dominantes preocupavam-se inicialmente com aspectos liberais para se verem livres dos monarcas e estados totalitários, sendo a educação reconhecida como um direito de todos somente no século XVIII, em 1763, na Prússia, sendo lá a primeira nação a reconhecer a obrigatoriedade do ensino primário público.

Já em terras nacionais, o Brasil iniciou a introdução do tema educacional em nossa legislação após a Segunda Guerra Mundial, especialmente por grande influência de tratados internacionais como a Declaração Universal dos Direitos Humanos, em 1948, a Declaração dos Direitos da Criança, de 1959 e, sobretudo, do Pacto Internacional sobre os Direitos Econômicos, Sociais e Culturais, de 1966, que por sua vez trouxeram questões ligadas ao reconhecimento expresso das garantias dos direitos individuais, buscando fundamento também em outras legislações 


\section{Personalidade Acadêmica Homenageada:}

Carlos Aurélio Mota de Souza (Universidade Ibirapuera - UNIB)

espalhadas pelo mundo, como Lei Fundamental Alemã, de 1949, da Constituição Portuguesa, de 1976 e da Constituição da Espanha, de 1978.

Neste particular, a educação passa então a ser declarada como um direito fundamental em nossa constituição de 1988 junto ao art. 6ํㅜ, reconhecendo-a com um suporte relevante para o desenvolvimento da nação, passando a destinar 9 artigos que tratariam especificamente sobre o tema como um direito social, descrevendo de forma clara que a educação é direito de todos e que sua prestação é um dever do Estado e da Família, tendo por escopo o pleno desenvolvimento da pessoa, seu preparo para o exercício da cidadania e sua qualificação para o trabalho, conforme descrito no art. 205.

Em sendo considerada a educação como um direito social, protegido por cláusula pétrea, o papel do Estado é oferecê-la de forma abrangente e gratuita, especialmente para os mais carentes, possibilitando que através do ensino se possa oferecer maiores possibilidades de ascensão econômica e diminuição da diferença abissal existente entre as classes sociais.

Destarte, surge ao cidadão a possibilidade de ter reconhecido o direito à educação e ao mesmo tempo poder exigir que essa prerrogativa the seja ofertada, posto que se trata de um direito público subjetivo, que por sua vez vem declarado no $\$ 1^{\circ}$ do art. 208 da Constituição, que define que o Estado é obrigado a oferecer o ensino público de forma gratuita para a educação básica. Essa gratuidade significa, por óbvio, que o Estado não pode solicitar qualquer contrapartida pelo serviço público da educação, sendo-Ihe vedada qualquer cobrança de taxas de matrícula ou outros valores destinados ao oferecimento e manutenção do ensino.

Assim, na hipótese do não oferecimento satisfatório desse direito público subjetivo, poderá o cidadão se socorrer dos remédios constitucionais como a ação popular, ação civil pública, mandado de segurança coletivo e o mandado de injunção, a fim de cessar ou amenizar a omissão Estatal e ver atendido seu direito de acesso à educação básica.

Porém, as obrigações decorrentes do direito à educação não são somente atribuídas ao Estado, tendo a família também papel importante nesse cenário, haja 


\section{Personalidade Acadêmica Homenageada:}

Carlos Aurélio Mota de Souza (Universidade Ibirapuera - UNIB)

vista que deve obrigatoriamente matricular os educandos em instituições de ensino e fazer o devido acompanhamento escolar, sob pena dos pais serem responsabilizados pelo crime de abandono intelectual ou outras sanções descritas na Lei de Diretrizes e Bases da Educação e no Estatuto da Criança e do Adolescente.

Importante ressaltar que a educação básica deve ser oferecida para todos em iguais condições, sem qualquer discriminação, devendo ainda ser ofertada para aqueles que não tiveram acesso na idade esperada, conforme determina o art. 208, I da constituição.

\section{CONSIDERAÇÕES FINAIS}

Embora com certo atrasado em relação ao resto do mundo, percebe-se que no Brasil a educação passou a ser encarada como um direito social somente após a Segunda Guerra Mundial, tendo a partir de então sido influenciada através de diversos tratados internacionais até que na atual constituição se tratou do tema com o devido grau de importância, destinando 9 artigos que tratam exclusivamente sobre o tema.

Destarte, garante ao individuo o reconhecimento da educação como um direito público subjetivo, permitindo o acesso obrigatório e gratuito, possibilitando, se necessário, que tal direito seja reclamado judicialmente através de ações constitucionais que tem o condão de forçar o Estado a cumprir sua função educacional.

O direito público subjetivo não só expressa a obrigação estatal para 0 oferecimento da educação, traz também mandamentos constitucionais dirigidos às famílias, como, por exemplo, a obrigatoriedade da matricula dos educandos nas instituições de ensino e o acompanhamento escolar, cujas normas encontram-se elencadas em leis ordinárias como o Código Penal, Lei de Diretrizes e Bases da Educação e no Estatuto da Criança e do Adolescente. 


\section{Personalidade Acadêmica Homenageada:}

Carlos Aurélio Mota de Souza (Universidade Ibirapuera - UNIB)

Ainda, sendo uma garantia social, o direito à educação deve respeitar o princípio da igualdade e ser ofertada para coletividade, em iguais condições, sem qualquer distinção de raça, sexo, idade ou cor, sendo, porém, devendo, porém, preferencialmente ser dirigida aos mais pobres, uma vez que visa diminuir a grande diferença econômica entre as classes sociais através do oferecimento de paridade de oportunidades.

PALAVRAS-CHAVE: Educação; Dever do Estado e da família; Direito social; Direito público subjetivo; Ensino gratuito e obrigatório.

\section{REFERÊNCIAS}

BRASIL, Constituição 1988 Disponível em: http://www.planalto.gov.br/ccivil03/constituicao/constituicao.htm. Acesso em 01 ago. 2018.18.

BRASIL, Lei 8.069, de 13 de julho de 1990. Dispõe sobre o Estatuto da Criança e do Adolescente e dá outras providências. Disponível em https://www.planalto.gov.br/ccivil_03/leis/L8069Compilado.htm. Acesso em 04 ago. 2018.

BRASIL, Lei no 9394, de 20 de dezembro de 1996. Lei de diretrizes e bases da educação nacional.

Disponível em: http://www.planalto.gov.br/ccivil_03/leis/L9394.htm. Acesso em: 04 ago. 2018.

BOSI, Alfredo. A educação e a cultura nas constituições brasileiras. Cultura brasileira: temas e situações. 2. ed. São Paulo, Ática, 1992.

CURY, Carlos Roberto Jamil. O direito à educação: um campo de atuação do gestor educacional na escola. Brasília: Escola de gestores, 2005. Disponível em < http://egov.ufsc.br/portal/sites/default/files/jamilcury.pdf. Acesso em 07 ago. 2018.

DA SILVA, Monica Ribeiro. Direito à educação, universalização e qualidade: cenários da Educação Básica e da particularidade do Ensino Médio. Jornal de Políticas Educacionais, v. 9, n. 17/18, 2016. 
Personalidade Acadêmica Homenageada:

Carlos Aurélio Mota de Souza (Universidade Ibirapuera - UNIB)

DUARTE, Clarice Seixas. A educação como um direito fundamental de natureza social. Educação \& Sociedade, v. 28, n. 100, p. 691-713, 2007. Disponível em http://www.scielo.br/pdf/es/v28n100/a0428100. Acesso me 08 ago. 2018.

GOMES, Fábio Guedes. Conflito social e welfare state: Estado e desenvolvimento social no Brasil. Revista de Administração Pública, v. 40, n. 2, p. 201-236, 2006. Disponível em http://www.scielo.br/pdf/rap/v40n2/v40n2a03. Acesso em 08 ago. 2018.

HORTA, José Silverio Baia. Direito à educação e obrigatoriedade escolar. Cadernos de Pesquisa, n. 104, p. 5-34, 1998. Disponível em https://dialnet.unirioja.es/servlet/articulo?codigo=6209182. Acesso em 08 ago. 2018

MELLO, Celso Antônio Bandeira de. Curso de Direito Administrativo, 9. ed. São Paulo. Malheiros Editores, 1997.

OLIVEIRA, Romualdo Portela de. O Direito à Educação na Constituição Federal de 1988 e seu restabelecimento pelo sistema de Justiça. Revista Brasileira de Educação, v. 11, p. 61-74, 1999. Disponível em http://www.egov.ufsc.br/portal/sites/default/files/anexos/30315-31270-1-PB.pdf. Acesso em 10 ago. 2018

PIOVESAN, Flávia. Direitos humanos e do direito constitucional internacional. 14 ed., rev. e atual. São Paulo, Saraiva, 2013.

TAVARES, André Ramos. Direito fundamental à educação. Direitos sociais: fundamentos, judicialização e direitos sociais em espécie. Rio de Janeiro: Lumen Juris, p. 771-788, 2008. Disponível em http://animaopet.com.br/pdf/anima1/artigo_Andre_Ramos_Tavares_direito_fund.pdf. Acesso em 06 ago. 2018 